\title{
PRISÃO PREVENTIVA EM FACE AO PRINCÍPIO DA PRESUNÇÃO DE INOCÊNCIA
}

Michael Henrique Lima Costa

Universidade do Oeste Paulista - UNOESTE, Curso de Direito, Presidente Prudente/SP.

\section{RESUMO}

O presente artigo tem por objetivo estudar a decretação da prisão provisória, mesmo quando em conflito com o princípio da presunção de inocência. Utilizou-se o método de abordagem dedutivo, uma vez que se partiu de aspectos gerais para específicos. A pesquisa, quanto ao procedimento utilizado na coleta de dados, é a bibliográfica. $O$ estudo foi realizado de forma a obter informações acerca dos tipos de prisão provisória, princípios constitucionais inerentes à prisão e, por fim, buscou-se saber sobre a legalidade ou não da prisão provisória à luz do princípio da presunção de inocência. Com base na pesquisa, conclui-se que os entendimentos relacionados ao assunto são variados, ora entendendo pela possibilidade da decretação da prisão provisória, ora a proibindo-a. Percebeu-se que tal prisão poderá ser decretada para garantir os fins da instrução criminal e esse é o argumento dos que são a favor. No entanto, para alguns, mesmo que se admita tal previsão, sua aplicação deve ser proibida em face da afronta ao princípio da presunção de inocência, constitucionalmente previsto. Assim, entende-se que há grande problemática relacionada ao tema, os quais devem ser ponderados pelo magistrado no momento da decretação da prisão.

Palavras-Chave: prisão preventiva; prisão em flagrante; prisão temporária; princípios constitucionais; princípio da presunção de inocência.

\begin{abstract}
The purpose of this article is to study the decree of provisional arrest, even when in conflict with the principle of presumption of innocence. The method of deductive approach was used, since it went from general to specific aspects. The research, regarding the procedure used in data collection, is the bibliographical one. The study was conducted in order to obtain information about the types of provisional arrest, constitutional principles inherent in the arrest and, finally, sought to know about the legality or not of the provisional arrest in light of the principle of presumption of innocence. Based on the research, it is concluded that the understandings related to the subject are varied, sometimes understanding the possibility of the decree of provisional arrest, sometimes prohibiting it. It has been realized that such arrest may be decreed to guarantee the ends of the criminal investigation and that is the argument of those who are in favor. However, for some, even if such a provision is admitted, its application should be prohibited in view of the breach of the principle of presumption of innocence, constitutionally foreseen. Thus, it is understood that there are great problems related to the subject, which must be weighed by the magistrate at the time of the arrest.
\end{abstract}

Keywords: Pre-trial detention; Jail in the act; Temporary arrest; constitutional principles; the presumption of innocence principle. 


\section{INTRODUÇÃO}

O presente TRABALHO oferecerá considerações essenciais á legalidade ou não da prisão preventiva de acordo com o principio da presunção da inocência.

Assim sendo analisados o que são as Prisões Cautelares,cujo os requisitos para a sua configuração, são os mesmos requisitos de todas as medidas cautelares, ou seja, o (fumus boni iuris, que é comprovada da materialidade do crime e sinais de sua autoria) e o (periculum in mora, que é o risco de decisão lenta, perigo em razão da demora.). mais especificamente, a, a Prisão em Flagrante, a Prisão Temporária, Prisão Preventiva e por fim, a legalidade ou não da prisão preventiva à luz do princípio da presunção de inocência.

\section{MODALIDADES PRISÃO CAUTELAR}

\subsection{PRISÃO EM FLAGRANTE}

Conceito: É uma prisão que consiste na restrição da liberdade de alguém, independente de ordem judicial, possuindo natureza cautelar, desde que esse alguém esteja cometendo, tenha acabado de cometer ou seja perseguido (ou mesmo encontrado) em situação (ou na posse de elementos) que faça presumir o cometimento da infração penal (CPP, art.302).

Já o artigo 302 do Código de Processo Penal, nos trás as espécies de prisão em flagrante, onde são considerados em flagrante delito quem:

I) está cometendo a infração penal;

II) acaba de cometê-la.

III) é perseguido, logo após, pela autoridade, pelo ofendido ou

por qualquer pessoa, em situação que faça presumir ser autor

da infração.

IV) é encontrado, logo depois, com instrumentos, armas,

objetos ou papéis que façam presumir ser ele autor da infração.

A prisão em flagrante também é uma espécie de medida restritiva da liberdade, de natureza cautelar e processual, em que consiste na prisão, sem necessidade de ordem do juiz competente.

\subsection{PRISÃO TEMPORÁRIA}

A prisão temporária é outra modalidade de prisão cautelar. Ao oposto da prisão preventiva e prisão em flagrante, ela não está disposta no Código de Processo Penal, mas sim, em uma Lei específica para ela. Trata-se da Lei no 7.960/89

A prisão temporária veio para suprir, legalmente, a antiga prisão para averiguação. E, ainda, na prisão temporária ocorre no período das investigações policiais, ou seja, antes do início do processo.

Por ser uma medida cautelar e provisória, a prisão temporária tem a finalidade de cautelar para as investigações do inquérito policial (segundo o artigo 1ㅇ, inciso I, da Lei no 7.960/89) e, ainda, de ser passageira, pois tem a sua duração é fixada em lei, como observado no artigo 2ㅇ da Lei oㅗ 7.960/89 e, também, no artigo 2으, § 3ㅇda Lei no 8.072/90 (Lei dos Crimes Hediondos).

Na prisão temporária, por ser também uma prisão cautelar, é estabelecido para a sua configuração, os mesmos requisitos de todas as medidas cautelares, ou seja, o fumus comissi delicti (fumus boni iuris, que é comprovada da materialidade do crime e sinais de sua autoria) e o periculum libertatis (periculum in mora, que é o risco de decisão lenta, perigo em razão da demora).

A prisão temporária tem como objetivo privar o acusado da sua liberdade de locomoção, com o finalidade de tornar mais eficaz as investigações de crimes graves no decorrer do inquérito policial. 
De acordo com essa lei, será cabível prisão temporária nas hipóteses elencadas abaixo: "Quando for imprescindível para as investigações durante o inquérito policial, ou seja, quando houver indícios de que, sem a prisão, as diligências serão mal sucedidas; Quando o indiciado não tiver residência fixa ou não fornecer elementos necessários ao esclarecimento de sua identidade;

Quando houver indícios de autoria ou de participação de um dos seguintes crimes: homicídio doloso, seqüestro ou cárcere privado, roubo, extorsão ou extorsão mediante seqüestro, estupro, epidemia ou envenenamento de água ou alimento, quadrilha, genocídio, tráfico de entorpecentes ou crime contra o sistema financeiro.

Também aceita a possibilidade de prisão temporária em caso de crime de terrorismo, tortura, bem como, em todos os crimes hediondos, conforme ordena a lei no 8072/90 em seu artigo 2, § 4으,

Vale sempre explica, que a prisão temporária é uma das formas de prisão processual, assim como é a prisão preventiva e a prisão em flagrante.

O prazo de duração de uma prisão temporária é de 5 dias, sendo possível prorrogá-la pelo mesmo período, lembrando que este prazo não será incluso naquele que se faz necessário para a conclusão da instrução criminal.

Nos casos dos crimes hediondos a prisão temporária será de 30 dias, prorrogável por mais 30 dias em caso de necessidade.

\subsection{PRISÃO DOMICILIAR}

A prisão domiciliar do art. 117, da LEP, "substitui" o cumprimento da pena em casa de albergado (regime aberto) e tem natureza de prisão-pena.

É cabível para condenados maiores de 70 anos (limite etário este não alterado pelo Estatuto do Idoso); condenados acometidos de doença grave; condenadas com filho menor ou deficiente (em razão do princípio da isonomia, abrange os condenados, desde que comprove a dependência do filho); condenadas gestantes.

Por outro lado, a prisão domiciliar do art. 317, do CPP, "substitui" a prisão preventiva e tem natureza de medida cautelar.

É cabível para acusados maiores de 80 anos de idade; acusados extremamente debilitados por doença grave; acusados com filhos menores de seis anos ou deficientes; e acusadas gestantes no sétimo mês ou gravidez de risco.

Dispõe o art. 117, da lei no 7.210/84, que:

Art. 117- Somente se admitirá o recolhimento do beneficiário de regime aberto em residência particular quando se tratar de:

I - condenado maior de 70 (setenta) anos;

II - condenado acometido de doença grave;

III - condenada com filho menor ou deficiente físico ou mental;

IV - condenada gestante.

Por sua vez, o art. 318, do CPP, preceitua que:

Art. 318 - Poderá o juiz substituir a prisão preventiva pela domiciliar quando o agente for:

I - maior de 80 (oitenta) anos;

II - extremamente debilitado por motivo de doença grave;

III - imprescindível aos cuidados especiais de pessoa menor de 6 (seis) anos de idade ou com deficiência;

IV - gestante a partir do $7^{\circ}$ (sétimo) mês de gravidez ou sendo esta de alto risco. 
Conclui-se que as conjecturas de cabimento da prisão domiciliar do art. 117, da lei no 7.210/84, devem ser aprovadas para fins de permissão da prisão domiciliar prevista no art. 317, do Código de Processo Penal, sob pena de infração ao princípio da não culpabilidade e ao princípio da razoabilidade, tão caros ao Estado Democrático de Direito.

\subsection{PRISÃO PREVENTIVA}

A prisão preventiva é uma espécie de prisão cautelar de natureza processual, sendo a mais importante delas. Esse tipo de prisão processual é unido a uma medida restritiva de liberdade que é apontada pelo juiz.

Essa determinação pode acontecer tanto na fase do inquérito policial como o da instrução criminal. Ela acontece como medida de segurança processual para assegurar eventual execução de pena, garantindo a conveniência da instrução criminal, e guardando a ordem pública e econômica.

a prisão preventiva é um meio de garantir que o acusado não fuja, e também, para garantir que o acusado não coaja testemunhas. Sempre devendo haver o indício suficiente de autoria e da materialidade do crime.

É fundamentada no Código de Processo Penal, nos artigos 311 a 316.

E, o seu artigo 312 assim o diz:

Art. 312 - Prisão preventiva poderá ser decretada como garantia da ordem pública, da ordem econômica, por conveniência da instrução criminal, ou para assegurar a aplicação da lei penal, quando houver prova da existência do crime e indicio suficiente de autoria.

Entende-se que a prisão preventiva é estabelecida em uma comprovada necessidade que vem da própria sociedade.

E essa necessidade de se obter uma prisão preventiva, é vista quando se avalia os pressupostos, fumus boni iuris, que é comprovada da materialidade do crime e sinais de sua autoria, e do periculum in mora, que é o risco de decisão lenta, perigo em razão da demora.

Conforme o artigo 311 do Código de Processo Penal, entende-se que a prisão preventiva sempre deve ser estabelecida pelo juiz (devido a jurisdicionalidade), pode ser feita de ofício (pelo próprio entendimento do juiz), como também a solicitação do Ministério Público ou do querelante, e ainda, a representação da autoridade policial.

Ainda, de acordo com o artigo 313 do Código de Processo Penal, é aceita a prisão preventiva nos casos do acusado ser reincidente em crime doloso, e também, se o crime envolver violência doméstica e familiar contra a mulher.

Havendo prova nos autos de que o individuo agiu de legítima defesa, sob estado de necessidade, ou ainda, por rigoroso cumprimento do dever legal, não caberá a prisão preventiva, de acordo com a regra citada no artigo 314 do Código de Processo Penal.

O último artigo que aborda a prisão preventiva no Código de Processo Penal é o artigo 316, e ele mostra que não havendo mais a necessidade da prisão preventiva, deverá esta ser revogada pelo juiz.

Porém, havendo novamente a necessidade, poderá ser decretada outra vez, de maneira bem fundamentada $\mathrm{E}$ é quanto à fundamentação que trata o artigo 315 do Código de Processo Penal, assegura que o despacho que decretar ou recusa a prisão preventiva, deverá ser sempre bem fundamentado, como consta também no artigo 93, inciso IX da Constituição Federal.

A prisão preventiva apenas será estabelecida, perante suma necessidade.

Sendo assim, se afirma que ela somente seja usada como medida de prevenção, e não como pena. 
Quanto à fase do inquérito policial, podemos observar que a partir do momento da decretação da prisão preventiva, há um prazo de 10 (dez) dias, no âmbito estadual, para o término do mesmo.

No âmbito federal, o prazo é de 15 (quinze) dias. No caso do Ministério Público se faz necessário pedir novas diligências por falta de indícios de autoria, com o inquérito policial já concluído, não caberá a prisão preventiva.

\section{PRISÃO PREVENTIVA}

\subsection{CONCEITO}

Ou seja, A prisão preventiva é uma maneira de prisão cautelar de natureza processual, consistente na medida restritiva de liberdade, em qualquer fase da investigação policial ou do processo penal, a ser decretada pelo juiz, de ofício, se no curso da ação penal, ou a requerimento do Ministério Público, do querelante ou do assistente, ou por representação da autoridade policial.

A preventiva só poderá ser decretada quando houver prova da existência do crime e indícios suficientes de autoria.

A preventiva não poderá ultrapassar 180 dias, se decretada no curso da investigação ou antes da sentença condenatória recorrível; ou de 360 dias, se decretada ou prorrogada por ocasião da sentença condenatória recorrível.

Esses períodos poderão ser prorrogado, mas vale lembrar que o juiz, ao constituir ou prorrogar prisão preventiva, já deverá, logo de início, indicar o prazo de duração da medida.

A prisão preventiva que exceder a 90 dias será obrigatoriamente reexaminada pelo juiz ou tribunal competente, que deverá analisar se continuam ou não os motivos determinantes da sua aplicação, podendo substituí-la, se for o caso, por outra medida cautelar.

$\mathrm{O}$ atual CPP não estipula prazos para a prisão preventiva; a jurisprudência, no entanto, tem fixado em 81 dias o prazo desse instituto até o final da instrução criminal.

\subsection{DA PRESUNÇÃO DE INOCÊNCIA}

O Princípio da Presunção de Inocência é conhecido como Princípio do Estado de Inocência ou da Não Culpabilidade. A constituição federal estabelece este princípio em seu artigo 5o, LVII(57), In verbis: Artigo 50, LVII(57):Ninguém será considerado culpado até o trânsito em julgado de sentença penal condenatória, consagrando a presunção de inocência

Ou seja que o acusado é inocente durante o desenvolvimento do processo e seu estado só se modifica por uma sentença final que o declara culpado.

Portanto, o Princípio da Presunção de Inocência, é o direito de não ser declarado culpado senão mediante sentença judicial com o trânsito em julgado, ao termino do devido processo penal.

podemos apontar três exigências decorrentes da previsão constitucional da presunção de inocência:

1. O ônus da prova dos fatos constitutivos da pretensão penal pertence com exclusividade à acusação, sem que se possa exigir a produção por parte da defesa de provas referentes a fatos negativos (provas diabólicas);

2. Necessidade de colheita de provas ou de repetição de provas já obtidas perante o órgão judicial competente, mediante o devido processo legal, contraditório e ampla defesa;

3. Absoluta independência funcional do magistrado na valoração livre das provas. 


\section{PRISÃO PREVENTIVA EM FACE AO PRINCÍPIO DA PRESUNÇÃO DE INOCÊNCIA}

O Princípio da Presunção de Inocência é conhecido como Princípio do Estado de Inocência ou da Não Culpabilidade. A constituição federal estabelece este princípio em seu artigo 5으, LVII(57):

Artigo 50, LVII(57):Ninguém será considerado culpado até o trânsito em julgado de sentença penal condenatória.

Quanto à prisão preventiva em face do Princípio Constitucional da Presunção de Inocência, ao verificar que não há violação ao mencionado princípio, e seja, decretada de acordo aos pressupostos a toda medida, cautelar (fumus boni iuris e periculum in mora) e os requisitos legais para a decretação

O Código de Processo Penal no seu artigo 316 dispõe que o juiz poderá revogar a prisão preventiva se, no decorrer do processo, verificar a falta de motivo para que subsista, poderá decretá-la novamente em caso de necessidade.

\section{CONCLUSÃO}

Depois da elaboração deste artigo, é possível concluir de início, que as prisões cautelares, apesar de apresentarem um possível conflito com o princípio da presunção de inocência do acusado, são necessárias para o melhor funcionamento do processo penal brasileiro.

Concluindo, especificamente, sobre a prisão preventiva, nota-se que ela é uma medida excepcional, servindo para garantir a instrução criminal e uma efetividade na aplicação da pena.

Assim, observa-se que, para que um Juiz aplique de forma correta a prisão preventiva, ele deve seguir alguns passos: Sempre que for utilizar-se da prisão preventiva, deve notar o artigo 313 do Código de Processo Penal o permite para isso. E, ainda, observar se o fumus boni iur is e periculum in mora estão presentes no caso concreto.

pode tratar da garantia da ordem pública, ou da ordem econômica, ou da necessidade de assegurar a instrução criminal, ou, ainda, de assegurar a aplicação da lei penal.

Vale lembrar, como já foi visto no trabalho, que o fumus comissi delicti (também chamado de fumus boni iur is), trata da prova de existência do crime e dos indícios suficientes de autoria do crime. $E$, o periculum libertatis (também + chamado de periculum in mora),

Completados esses requisitos, a prisão preventiva deve ser decretada pelo Juiz, lembrando que sempre deve ser muito bem fundamentada, pois isso também é um requisito para a mesma.

Já sobre o princípio da presunção de inocência do acusado, observamos que ele tem como principal idéia, a de que ninguém poderá ser considerado culpado antes da sentença transitada em julgado. Assim, o citado princípio serve para proteger o acusado, para evitar que ele acabe sendo submetido a uma pena que é adotada para quem já foi condenado

\section{REFERÊNCIAS}

BONFIM, Edílson Mougenot. Curso de processo penal. 5a Ed. São Paulo: Saraiva, 2009.

BRASIL. Constituição da república federativa do brasil. Casa Civil. Disponível em:<http://www.planalto.gov.br/ccivil_03/constituicao/constitui\%C3\%A7ao.htm. Acesso em 02/04/2017.

CAPEZ, Fernando. Curso de processo penal. 12a Ed. rev. e atual. São Paulo: Saraiva, 2005.

Declaração dos direitos do homem e do cidadão. Disponível em< http://www.portalsaofrancisco.com.br/alfa/dezembro/dia-da-declaracao-universal-dos-direitosdo-homem.php. Acesso em 04/03/2017. 
Declaração dos direitos do homem e do cidadão. Disponível em<http://educacao.uol.com.br/histori. Acesso em 08/03/2017.

GOMES FILHO, Antônio Magalhães. Presunção de Inocência e prisão cautelar. São Paulo: Saraiva, 2009.

LOPES JUNIOR, Aury. Prisões cautelares. 4ạ Ed. rev. e atual. São Paulo: Saraiva, 2013.

MARTINS, Jorge Henrique Schaefer. Prisão provisória: medida de exceção no direito criminal brasileiro. Curitiba: Juruá, 2004.

MIRABETE, Júlio Fabbrini. Processo penal. 18a Ed. São Paulo: Atlas, 2012.

MORAES, Alexandre de. Direito constitucional. 24a Ed. São Paulo: Atlas, 2009.

Direitos humanos fundamentais: teoria geral. 5a Ed. São Paulo: Atlas,

2003.

NUCCl, Guilherme de Souza. Manual de processo penal e execução penal. 6a Ed. São Paulo: Revista dos Tribunais, 2010.

OLIVEIR, Eugênio Pacelli. Curso de processo penal. 11a Ed. Rio de Janeiro: Lumem Júris, 2009.

RANGEL, Paulo. Direito processo penal. 7ạ Ed. rev. Amp. e atual. Rio de Janeiro: Lumen Juris, 2003.

2009. Direito processual penal. 16aㅡ Ed. ver. Ampl. e atual. Rio de Janeiro: Lúmen Júris,

TOURINHO FILHO, Fernando da Costa. Código de Processo penal comentado. 7ạ Ed. rev. aum. e atual. São Paulo: Saraiva, 2003.

Fernando da Costa. Processo penal. 31ạ Ed. rev. e atual. São Paulo: Saraiva,

2009.

TORNAGHI, Hélio Bastos. Instituições de processo penal. 6ạ Ed. São Paulo: Saraiva, 1989.

VILAS BOAS, Marco Antônio. Processo penal completo. São Paulo: Saraiva, 2001. 